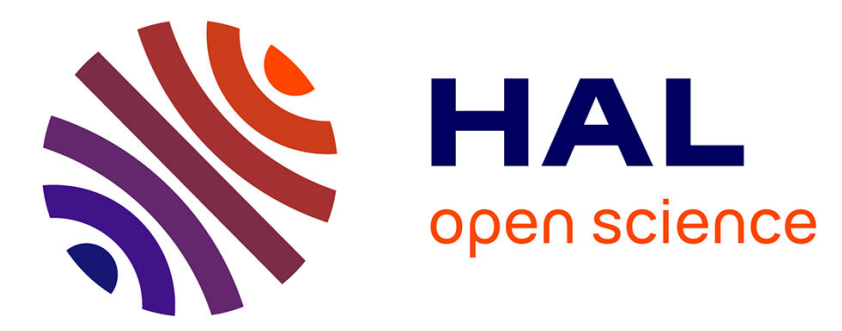

\title{
Thermal expansion and stress development in the first stages of silicidation in Ti/Si thin films
}

Bernard Chenevier, Odette Chaix-Pluchery, Patrice Gergaud, Olivier Thomas, Francesco La Via

\section{- To cite this version:}

Bernard Chenevier, Odette Chaix-Pluchery, Patrice Gergaud, Olivier Thomas, Francesco La Via. Thermal expansion and stress development in the first stages of silicidation in $\mathrm{Ti} / \mathrm{Si}$ thin films. Journal of Applied Physics, 2003, 94 (11), pp.7083. 10.1063/1.1625092 . hal-00207862

\section{HAL Id: hal-00207862 https://hal.science/hal-00207862}

Submitted on 18 Jan 2008

HAL is a multi-disciplinary open access archive for the deposit and dissemination of scientific research documents, whether they are published or not. The documents may come from teaching and research institutions in France or abroad, or from public or private research centers.
L'archive ouverte pluridisciplinaire HAL, est destinée au dépôt et à la diffusion de documents scientifiques de niveau recherche, publiés ou non, émanant des établissements d'enseignement et de recherche français ou étrangers, des laboratoires publics ou privés. 


\title{
THERMAL EXPANSION AND STRESS DEVELOPMENT IN THE
}

\section{FIRST STAGES OF SILICIDATION IN Ti/Si THIN FILMS}

\author{
B. Chenevier ${ }^{\mathrm{a}}$, O. Chaix-Pluchery ${ }^{\mathrm{a}}$, P. Gergaud ${ }^{\mathrm{b}}$, O. Thomas ${ }^{\mathrm{b}}$, F. La Via ${ }^{\mathrm{c}}$ \\ ${ }^{a}$ LMGP, CNRS - INPG, BP 46, Saint-Martin d'Hères Cedex, F-38402, France \\ ${ }^{\mathrm{b}}$ TECSEN, CNRS, Université d'Aix-Marseille III, F-13397 Marseille Cedex 20, France

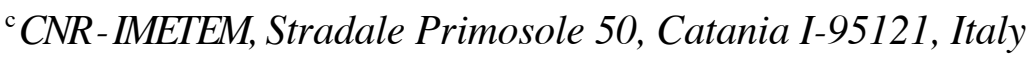 \\ * Corresponding author - e-mail: Odette.Chaix@inpg.fr
}

\begin{abstract}
The structural evolution in fiber-textured Ti/Si thin films has been investigated by in-situ X-ray diffraction, in a temperature range preceding the formation of silicide compounds. At low temperature, thermoelastic behavior of the metallic film was observed. Abnormal thermal behavior of both 002 and 101 diffraction profiles was observed at $360^{\circ} \mathrm{C}$ and $450^{\circ} \mathrm{C}$, which could be understood in terms of Si diffusion, first in Ti grain boundaries, then, into the grains. By combining ex-situ strain studies with analysis of the Si local environment in the whole $\mathrm{Ti}$ silicide family from $\mathrm{Ti}_{5} \mathrm{Si}_{3}$ to $\mathrm{TiSi}_{2}$, it was possible to determine the stressfree lattice parameters of annealed films. They are significantly higher than the bulk parameters, and indicate that nearly 4.5 at. $\% \mathrm{Si}$ is present in the Ti grains.
\end{abstract}

\section{Keywords:}

Silicidation, X-ray diffraction, Si diffusion, stress/strain analysis. 


\section{Introduction}

Careful investigations of metal/silicon reactivity are important for in-depth understanding of the silicide formation in thin film systems because electrical properties of silicide based contacts are strongly dependent on film characteristics such as the residual stress developed during silicidation. This topic has been the object of many studies, as reviewed in reference ${ }^{1}$. In most systems, and specially in the case of $\mathrm{Ti} / \mathrm{Si}$, compressive stresses occur during silicide formation. Investigations about the effects of stress on the growth of $\mathrm{TiSi}_{2}$ thin films show a strong influence on the growth kinetics of silicide and therefore, on its formation temperature.

Our recent studies related to titanium silicide formation were carried out using in-situ X-ray diffraction (XRD). Thermal expansion investigations were done from a sample progressively annealed from room temperature up to $630^{\circ} \mathrm{C}$. $\mathrm{C} 49 \mathrm{TiSi}_{2}$ started to be detected at $\mathrm{T}=540^{\circ} \mathrm{C}$ and the transformation to the $\mathrm{C} 54$ phase took place at $630^{\circ} \mathrm{C}$. The $\mathrm{C} 49$ thermal expansion coefficients exhibited a clear anisotropy correlated with the presence of planar defects perpendicular to the large b-axis of the unit-cell, observed by Transmission Electron Microscopy (TEM) ${ }^{2,3}$. The C49-C54 transition is associated with a volume cell reduction close to $1.6 \%$ at the transition temperature, indicating that the transformation is of first order ${ }^{2,4}$. Additional TEM observations gave evidence that both phases coexist with a third crystalline component indexed as $\mathrm{Ti}_{5} \mathrm{Si}_{3}{ }^{3,4}$.

The present paper reports on an XRD analysis of the Ti structural evolution in a temperature range preceding the silicide formation. As titanium is known to be one of the slowest diffusing transition metal in silicon ${ }^{5}$, it seems reasonable to consider that silicon is the fast-moving species in this temperature range. Some papers have reported the occurrence of significant interdiffusion/intermixing at temperatures close to $400^{\circ} \mathrm{C}$ in thin $\mathrm{Ti}$ layers on $\mathrm{Si}$ substrate ${ }^{6}$, and at $455^{\circ} \mathrm{C}$ in $\mathrm{Ti}-\mathrm{Si}$ multilayers ${ }^{7}$, leading to the formation of amorphous or extremely fine grain microstructure alloy with a composition close to TiSi.

Results of in-situ and ex-situ stress/strain analysis were combined with detailed investigations of the $\mathrm{Si}$ local environment in the whole silicide family from $\mathrm{Ti}_{5} \mathrm{Si}_{3}$ to $\mathrm{TiSi}_{2}$ in order to understand how $\mathrm{Si}$ diffusion possibly takes place before the formation of crystalline silicides.

\section{Experiments and methods}

\section{2-a Experimental procedure}

As-deposited samples were obtained by sputtering $100 \mathrm{~nm}$-thick Ti films on (100) Si substrates capped with a $250-\mathrm{nm}$ thick amorphous Si film. The Ti films were covered by a nominally 25 -nm thick TiN film. The initial Ti metal films exhibited a high degree of (002) and (101) preferred orientation of fiber type with no in-plane orientation, according to X-ray analysis. TEM observations showed a pronounced columnar texture characterised by a high density of grain boundaries extending from the Simetal interface to the TiN surface ${ }^{3}$. From the measured $002 / 101$ intensity ratio $(\approx 3)$ and the diffraction 
powder data $\left(\mathrm{I}_{002} / \mathrm{I}_{101} \approx 0.4\right)$, the estimated volume fractions were roughly $90 \%$ (002) and $10 \%$ (101). The TiN film had a columnar texture and (111) preferred orientation. The $111 \mathrm{TiN}$ reflection did not show any marked change aside from the expected thermoelastic shift.

In-situ XRD experiments were conducted using a high-temperature diffraction stage and a positionsensitive detector (INEL, CPS 120) spanning a $120^{\circ}$ aperture and a conventional X-ray tube $\left(\lambda_{\mathrm{FeK} \alpha}=0.1936 \mathrm{~nm}\right)$. The fixed incident angle is set up to $\left(\theta_{002}+\theta_{101}\right) / 2$. Specifications of the heating stage are given elsewhere ${ }^{4}$. Samples were annealed in a slightly reducing gaseous atmosphere to preserve the TiN layer from oxidation.

The thermal investigations were done on samples initially at room temperature, progressively annealed by applying repeated sequences of temperature ramps followed by stabilisation. The typical temperature range between two stabilisations was $10^{\circ} \mathrm{C}$. The samples were heated following this procedure up to the $\mathrm{C} 49$ phase detection, i.e. at temperatures close to $540^{\circ} \mathrm{C}$. Diffraction patterns were recorded for $800 \mathrm{~s}$ at each stabilisation step.

Stress/strain analysis was made from X-ray diffraction data recorded ex-situ on a conventional three-circle $(\theta / 2 \theta / \phi)$ X-ray diffractometer $\left(\lambda_{\mathrm{FeK} \alpha}=0.1936 \mathrm{~nm}\right)$. Strains at high $\psi$ values were obtained from a four-circle diffractometer $\left(\lambda_{\mathrm{Cu}}=0.15406 \mathrm{~nm}\right)$. Diffraction profiles were thus obtained in symmetric and asymmetric diffraction geometry. The in-plane anisotropy was evaluated.

\section{2-b Thermal expansion}

As our in-situ XRD method provides us with unit-cell variations perpendicular to the film, we have tried to calculate the expected linear thermal dependence of perpendicular variations, accounting for the film adherence onto the substrate. It is thus necessary to include thermoelastic effects in the observed thermal expansion. This calculation assumes that the in-plane expansion of the film is imposed by the substrate since the adhesion is assumed to be perfect:

$$
\mathrm{L}_{\mathrm{f}}(\mathrm{T})=\mathrm{LS}_{S}(\mathrm{~T})=\mathrm{L}_{\mathrm{S}}^{0}(\mathrm{~T})=\mathrm{L}_{\mathrm{S}}^{0}\left(\mathrm{~T}_{0}\right)\left(1+\alpha_{\mathrm{S}} \Delta \mathrm{T}\right)
$$

where $\operatorname{Lf}_{f}(T), L_{S}(T)$ and $\mathrm{L}_{S}^{0}(T)$ describe the thermal dependence of the film, substrate and stress-free substrate unit-lengths, respectively. $\alpha_{S}$ is the thermal expansion coefficient of the substrate and $\Delta \mathrm{T}=\mathrm{T}-\mathrm{T}_{0}$ is the temperature increase from room temperature $\mathrm{T}_{0}$. The stress-free film length $\mathrm{L}_{\mathrm{f}}^{0}(\mathrm{~T})$ is expressed as

$$
\mathrm{L}_{\mathrm{f}}^{0}(\mathrm{~T})=\mathrm{L}_{\mathrm{f}}^{0}\left(\mathrm{~T}_{0}\right)\left(1+\alpha_{\mathrm{f}} \Delta \mathrm{T}\right)
$$

where $\alpha_{\mathrm{f}}$ is the thermal expansion coefficient of the film (here, $\alpha_{\mathrm{f}}=\alpha_{\mathrm{bulk} \text { Ti }}=8.510^{-6} \mathrm{~K}^{-1}$ ). Similarly, the thermal dependence of the film thickness is given by

$$
\mathrm{L}_{\mathrm{f}}^{0 \text { perp }}(\mathrm{T})=\mathrm{L}_{\mathrm{f}}^{0 \text { perp }}\left(\mathrm{T}_{0}\right)\left(1+\alpha_{\mathrm{f}} \Delta \mathrm{T}\right)
$$

The biaxial in-plane strain in the film is thus defined as 


$$
\varepsilon / /(\mathrm{T})=\frac{\mathrm{Lf}_{\mathrm{f}}(\mathrm{T})-\mathrm{L}_{\mathrm{f}}^{0}(\mathrm{~T})}{\mathrm{L}_{\mathrm{f}}^{0}(\mathrm{~T})}
$$

and the strain measured along the normal to the surface as

$$
\varepsilon_{\text {perp }}(T)=\frac{L_{f}^{\operatorname{perp}}(T)-L_{f}^{0 p e r p}(T)}{L_{f}^{0 p e r p}(T)}
$$

where $\mathrm{L}_{\mathrm{f}}^{\text {perp }}(\mathrm{T})$ and $\mathrm{L}_{\mathrm{f}}^{\text {Operp }}(\mathrm{T})$ have obvious meanings according to $\mathrm{L}_{\mathrm{f}}(\mathrm{T})$ defined previously. Additionally, in the case of equal biaxial strain state

$$
\varepsilon_{\text {perp }}(\mathrm{T})=\frac{-2 v}{1-v} \varepsilon / /(\mathrm{T}) \approx-\varepsilon / /(\mathrm{T})
$$

for the Ti film $\left(v_{\mathrm{Ti}}=0.34\right), v$ being the Poisson's ratio for the film material. $\mathrm{L}_{\mathrm{f}}^{\text {perp }}(\mathrm{T})$ extracted from Eqs 4 and 5 can be expressed under the form

$$
\mathrm{L}_{\mathrm{f}}^{\text {perp }}(\mathrm{T})=\mathrm{L}_{\mathrm{f}}^{0 \text { perp }}(\mathrm{T})(1-\varepsilon / /(\mathrm{T}))=\mathrm{L}_{\mathrm{f}}^{0 \text { perp }}\left(\mathrm{T}_{0}\right)\left(1+\alpha_{\mathrm{f}} \Delta \mathrm{T}\right)(1-\varepsilon / /(\mathrm{T}))
$$

Combining Eqs 3 and 6 results in

$$
\begin{aligned}
\mathrm{L}_{\mathrm{f}}^{\operatorname{perp}}(\mathrm{T}) & \approx \mathrm{L}_{\mathrm{f}}^{0 \operatorname{perp}}\left(\mathrm{T}_{0}\right)\left(1-\varepsilon_{/ /}\left(\mathrm{T}_{0}\right)\right)\left(1+\left(2 \alpha_{\mathrm{f}}-\alpha_{\mathrm{S}}\right) \Delta \mathrm{T}\right) \\
& =\mathrm{L}_{\mathrm{f}}^{\operatorname{perp}}\left(\mathrm{T}_{0}\right)\left(1+\left(2 \alpha_{\mathrm{f}}-\alpha_{\mathrm{S}}\right) \Delta \mathrm{T}\right)
\end{aligned}
$$

Defining $\alpha_{\mathrm{eff}}^{\text {perp }}$ as

$$
\mathrm{L}_{\mathrm{f}}^{\operatorname{perp}}(\mathrm{T})=\mathrm{L}_{\mathrm{f}}^{\text {perp }}\left(\mathrm{T}_{0}\right)\left(1+\alpha \operatorname{eff}_{\operatorname{perp}} \Delta \mathrm{T}\right)
$$

results in

$$
\alpha_{\text {eff }}^{\text {perp }}=2 \alpha_{f}-\alpha_{S}
$$

\section{2-c Stress analysis method}

A classical method for stress $(\sigma)$ and strain $(\varepsilon)$ determination using XRD is the well-known $\sin ^{2} \Psi$ method ${ }^{8,9}$. The ultimate goal here is to obtain the relationship between $\varepsilon_{\mathrm{ij}}$ and $\sigma_{\mathrm{k} 1}$ as a function of the $\psi$ angle: $\psi$ is the angle between the scattering plane and the normal to the sample. It relies on determining strains from accurate lattice spacings of planes that have normal in different $(\phi, \psi)$ directions. In the following, primed tensor quantities refer to the laboratory system $\mathrm{L}_{\mathrm{i}}$ and unprimed tensor quantities refer to the sample coordinate $S_{i}$ system. The laboratory system of axis $L_{i}$ is defined such that $L_{3}$ is in the direction of the normal to the family of planes (hkl) whose spacing is measured. $\mathrm{L}_{2}$ is in the plane defined by $S_{1}$ and $S_{2}$ at an angle $\phi$ from $S_{2}$. The axes $S_{i}$ define the surface of the specimen with $S_{1}$ and $S_{2}$ in this surface. The crystal system is defined by the a, c hexagonal axes and a third axis perpendicular to a and $\mathrm{c}$. It is common for the elastic compliances to be known in this reference frame. The lattice spacing $d_{\phi \psi}$ is obtained from the position of the diffraction peak for a given reflection hkl and the strain along $\mathrm{L}_{3}$ from :

$$
\left(\varepsilon_{33}^{\prime}\right) \phi \psi=\frac{\mathrm{d}_{\phi \psi}-\mathrm{d}_{0}}{\mathrm{~d}_{0}}
$$


$\mathrm{d}_{0}$ being the lattice spacing in the stress-free state. This strain may be expressed in terms of the strains $\varepsilon_{\mathrm{ij}}$ in the sample coordinate system by using a standard tensor rotation

$$
\left(\varepsilon_{33}^{\prime}\right)_{\phi \psi}=\mathrm{a}_{3 \mathrm{k}} \mathrm{a}_{31} \varepsilon_{\mathrm{k} 1}
$$

where $a_{3 k}, a_{31}$ are the direction cosines between $L_{3}$ and $S_{k}, S_{1}$, respectively. Substituting for $a_{3 k}, a_{31}$ in Eq. 11 leads to the fundamental equation of $\mathrm{X}$-ray strain determination

$$
\begin{array}{r}
\left(\varepsilon_{33}^{\prime}\right) \phi \psi=\frac{d_{\phi \psi}-d_{0}}{d_{0}}=\varepsilon_{11} \\
\cos ^{2} \phi \sin ^{2} \psi+\varepsilon_{12} \sin 2 \phi \sin ^{2} \psi+\varepsilon_{22} \sin ^{2} \phi \sin ^{2} \psi \\
+\varepsilon_{33} \cos ^{2} \psi+\varepsilon_{13} \cos \phi \sin 2 \psi+\varepsilon_{23} \sin \phi \sin 2 \psi
\end{array}
$$

The tensor relationship between stresses and strains is expressed with Hooke's law by either of these equivalent expressions

$$
\begin{aligned}
& \varepsilon_{i j}=S_{i j k l} \sigma_{k l} \\
& \sigma_{i j}=C_{i j k l} \varepsilon_{k l}
\end{aligned}
$$

where $S_{i j k l}$ and $C_{i j k l}$ are the elastic compliance and elastic stiffness fourth rank tensors which refer to the $S_{i}$ system of axes. The stress (or strain) state of an elastic body is completely described by the stress (or strain) tensor for any reference frame. The compliances and stiffnesses are generally known for the crystallographic reference frame, and they can be rotated to any desired reference frame by using

$$
\mathrm{S}_{\mathrm{ijkl}}=\mathrm{a}_{\mathrm{im}} \mathrm{a}_{\mathrm{jn}} \mathrm{a}_{\mathrm{ko}} \mathrm{a}_{1 \mathrm{p}} \mathrm{S}_{\mathrm{mnop}}
$$

where $a_{i j}$ are the direction cosines between the sample axes and the crystal axes and $S_{\text {mnop }}$ the compliance tensor defined in the crystal axes. There is no need to use this expression if the crystal axes coincide with the sample axes. By using symmetry considerations, the elastic stiffness and compliance terms are usually expressed with two subscripts (Voigt notation) instead of four ${ }^{10}$.

In hexagonal crystals, the compliance matrix can be described by only five terms: $S_{11}, S_{12}, S_{13}, S_{33}$, $\mathrm{S}_{44}\left(\mathrm{~S}_{66}=2\left(\mathrm{~S}_{11}-\mathrm{S}_{12}\right)\right)$. In the case of (001) oriented grains, it is given in Table 1a. As we are concerned with a thin film deposited on a substrate, no stress is applied on the free surface of the sample i.e. $\sigma_{33}=0$. Moreover, for a thin film in the particular case of equal biaxial stresses on the surface of the sample, $\sigma_{11}=\sigma_{22}=\sigma_{\phi}$ and all shear stress components vanish; then, the fundamental equation (12) for these grains can be reduced to :

$$
\varepsilon_{\Psi}=\left(\mathrm{S}_{11}+\mathrm{S}_{12}-2 \mathrm{~S}_{13}\right) \sin ^{2} \psi \sigma_{\phi}+2 \mathrm{~S}_{13} \sigma_{\phi}
$$

and stress can be derived from the slope of an $\varepsilon_{\Psi}$ plot as a function of $\sin ^{2}(\psi)$.

In addition to stress determination, the $\sin ^{2}(\psi)$ method allows the stress-free lattice parameters to be calculated. The so-called stress-free direction is obtained from $\varepsilon_{\Psi}=\varepsilon\left(\psi_{0}\right)=0$, which leads to :

$$
\sin ^{2} \Psi_{0}=\frac{-2 S_{13}}{S_{11}+S_{12}-2 S_{13}}
$$

In solid-state reactions such as those occurring in metal/Si systems, alloying may lead to modifications of the stress-free lattice parameters of the metal and $\mathrm{d}_{0}$ transforms into $\mathrm{d}_{0}{ }^{\prime}$, the stress-free 
'alloyed' lattice parameter (see for instance reference ${ }^{11}$ ). Alloying is thus usually detected in $\sin ^{2}(\psi)$ analysis from significantly non-zero values of $\varepsilon\left(\psi_{0}\right)$. By further assuming constraints on unit-cell parameters, it is possible to determine the alloyed unstressed parameters $\left(a_{0}^{\prime}\right.$ and $c_{0}^{\prime}$ in hexagonal crystals) and separate the chemical and mechanical contributions to d-spacings. This correction is performed by first calculating $\mathrm{d}_{0}{ }^{\prime}\left(\sin ^{2}\left(\psi_{0}\right)\right)$. Using an assumption of the type $\frac{\mathrm{c}^{\prime} 0}{\mathrm{a}_{0}^{\prime}}=\frac{\mathrm{c}}{\mathrm{a}}=$ constant , corrected $\varepsilon$ data can be recalculated for each X-ray reflection. In the new set of $\varepsilon$ data, $\varepsilon\left(\psi_{0}\right)=0$ and the mechanical stress can thus be obtained from the slope of the linear variations. Evaluating the alloying rate from the alloyed parameters requires incorporating further physical assumptions into the mechanism of intermixing.

In the following, we refer to (001) and (101) oriented Ti grains as G2 and G1 grains, respectively.

\section{Results and discussion}

Analysis of X-ray diffraction patterns associated with TEM observations made it possible to identify the successive crystallized silicide phases formed as the annealing temperature increases : $\mathrm{Ti}_{5} \mathrm{Si}_{3} \mathrm{first}_{\mathrm{s}}$ forms near $500^{\circ} \mathrm{C}$ as a thin crystalline layer, several $\mathrm{nm}$ thick, sandwiched in between an amorphous silicide layer well-known in Ti-Si, Ti-SiGe and other transition metal-Si systems ${ }^{12-14}$, about $20 \mathrm{~nm}$ thick, and the $\mathrm{Ti}$ film. Then, the $\mathrm{C} 49$ and $\mathrm{C} 54 \mathrm{TiSi}_{2}$ diffraction lines appear at $\mathrm{T}=540^{\circ} \mathrm{C}$ and $630^{\circ} \mathrm{C}$, respectively.

The Ti 002 and 101 diffraction profiles were analyzed as a function of annealing temperature in the whole temperature domain where no other crystalline phase was observed in the diffraction pattern. As seen in Fig. 1, three regimes can be distinguished in the thermal evolution of the angular positions:

I : As the annealing temperature progressively increases up to about $360^{\circ} \mathrm{C}$, a conventional thermal expansion is observed. The Ti reflections linearly shift to lower $2 \theta$ values as can be seen from the dspacing evolution in Fig. 1a. At the same time, their intensity slightly decreases (results not shown). A simple linear fit of the d-spacing evolution allows us to obtain 'effective' perpendicular thermal expansion coefficients along the normal to the film: $\left(\alpha_{002}^{\text {perp }}\right)_{\text {eff }}=12.610^{-6} \mathrm{~K}^{-1}$ for $\mathrm{G} 2$ grains, $\left(\alpha_{101}^{\text {perp }}\right)_{\text {eff }}=15.810^{-6} \mathrm{~K}^{-1}$ for G1 grains. These values have been compared to the value of $\alpha_{\mathrm{eff}}^{\text {perp }}=14$ $10^{-6} \mathrm{~K}^{-1}$ obtained from Eq. $9\left(\alpha_{\mathrm{eff}}^{\text {perp }}=2 \alpha_{\mathrm{f}}-\alpha_{\mathrm{S}}, \alpha_{\text {bulk Ti }}=8.510^{-6} \mathrm{~K}^{-1}, \alpha_{\mathrm{Si}}=310^{-6} \mathrm{~K}^{-1}\right)$. This value is in full agreement with the measured perpendicular thermal expansion coefficients given above. The full width at half maximum (FWHM) of both reflections is roughly constant in this temperature range (Fig. 1b). 
II : Above $360^{\circ} \mathrm{C}$, a large shift of the reflections towards lower angles is observed, corresponding to a rapid increase of the d-spacing values (Fig. 1a), i.e. to a Ti expansion higher than the thermal expansion itself.

III : From a temperature close to $450^{\circ} \mathrm{C}$ on, the expansion slows down (Fig. 1a) and the FWHM increases drastically (Fig. 1b). At the same time, the reflection intensities fall down.

Our focus here concerns the reaction steps corresponding to regimes II and III. They are analyzed in the following section with a particular emphasis on regime III.

\section{3-a Si diffusion along Ti grain boundaries}

The sharp variation in the unit-cell parameters above $360^{\circ} \mathrm{C}$ occurs when no crystalline phase such as metal-rich silicide is observed. Thus, the changes at $360^{\circ} \mathrm{C}$ only concern prereactional phenomena. In agreement with Rubloff's results ${ }^{6}, \mathrm{Si}$ diffusion in Ti grain boundaries is assumed, based on two considerations. First, defects such as local distortions or vacancies are usually present in the grain boundaries, which makes atomic diffusion easier. Second, a local volume increase between the Ti grains causes a lateral compressive stress on the grains. The latter would result in a d-spacing expansion in the perpendicular direction (Poisson effect) and then, in a reflection shift towards lower angles, which has indeed been observed.

At the maximum of the reflection shift ( $\mathrm{T}$ close to $450^{\circ} \mathrm{C}, \Delta 2 \vartheta=0.4^{\circ}$ ), the resulting 001 and 101 out-

of-plane strain $\left(\varepsilon_{\text {perp }}\right)$ has been calculated using Eq. 4. After correction of the thermal expansion effect (Eq. $2 \mathrm{~b}$ ), we obtain $\varepsilon_{\text {perp }}$ values close to 0.54 and $0.70 \%$, respectively. The corresponding compressive stress is $\sigma=-\frac{\mathrm{E}}{2 v} \times \varepsilon_{\text {perp }}$ i.e. $-877 \mathrm{MPa}$ and $-1.1 \mathrm{GPa}$, respectively, where $\mathrm{E}$ and $v$ are the Young's modulus and Poisson's ratio $(\mathrm{E}=110.4 \mathrm{GPa} ; \mathrm{v}=0.34$ for $\mathrm{Ti})$.

\section{3-b Si diffusion into Ti grains}

The drastic increase of the linewidths from $450^{\circ} \mathrm{C}$ can be either attributed to a Si composition gradient or to a strain gradient normal to the film as both assumptions give a distribution in interplanar spacings. We will show from stress measurements presented in Section 3-c/ how to discriminate between composition and strain effects.

Moreover, the reflection intensity considerably reduces before any signal of long-range ordered compound formation becomes detectable. This observation can be explained in terms of Si diffusion into the Ti grains in the sense that the diffusing $\mathrm{Si}$ subdivides the $\mathrm{Ti}$ grains into very fine $\mathrm{Ti}$ particles. Additionnally, this reduction cannot be attributed to a silicide compound formation because no contribution of any very fine $\mathrm{Ti}_{5} \mathrm{Si}_{3}$ particles has ever been observed in $\mathrm{Ti}$ layer in TEM micrographs recorded from samples annealed at this temperature. As the $\sin ^{2}(\Psi)$ method makes it possible to separate alloying and elastic components in d-spacings, this method has been applied to as-deposited and annealed samples. 


\section{3-c Ex-situ stress analysis}

To determine the stress developed in regime III, a sample was annealed at $478^{\circ} \mathrm{C}$ and quenched rapidly by suppressing the power supplied to the heating element of our ancillary equipment. Ex-situ diffraction measurements were then performed on the annealed sample.

Reflections were measured for both G1 and G2 Ti grains from as-deposited and annealed samples. No significant in-plane anisotropy in $\varepsilon$ values could be detected. This allowed us to use an in-plane isotropic model of deformation in both cases. The data processing of both grain types required nevertheless to distinguish G2 whose crystallographic planes parallel to the film/substrate interface are isotropic from $\mathrm{G} 1$ in which the same planes are anisotropic.

\section{G2 grains}

A plot of $\varepsilon$ versus $\sin ^{2} \Psi$, shown in Fig. 2, using $d_{0}$ values of bulk Ti as reference, exhibits two essential features :

(i) Application of Eq. 16 to G2 grains gives $\sin ^{2} \Psi_{0}=0.42$ (the elastic compliance values for Ti have been taken from reference $\left.{ }^{8}\right)$ and hence $\varepsilon\left(\psi_{0}\right)$ is nearly zero in the as-deposited sample, while it is largely positive for annealed films. $\varepsilon\left(\psi_{0}\right)>0$ indicates that the lattice parameter for the unstressed alloy is greater than that of the bulk un-alloyed Ti. This positive alloying effect can be understood in terms of incorporation of some $\mathrm{Si}$ into the Ti matrix, a situation made irreversible upon quenching.

(ii) Stresses have been obtained from the slope of $\varepsilon=f\left(\sin ^{2} \Psi\right)$ after correction of the alloying effect,

assuming $\frac{\mathrm{c}^{\prime} 0}{\mathrm{a} 0}=\frac{\mathrm{c}}{\mathrm{a}}=1.604$ (see Table 3). As the expected Si content in the Ti grains is probably small (see Ti-Si equilibrium phase diagram), elastic compliances of the alloyed Ti have been considered not significantly different from those of the pure Ti. Stresses are positive (+270 MPa) and negative (-155 $( \pm 50) \mathrm{MPa}$ ) for the as-deposited and annealed films, respectively. The thermoelastic stress between room temperature and $478^{\circ} \mathrm{C}$ is negative and the annealed grains must therefore be under a compressive stress at the annealing temperature. Assuming no debonding at the Ti/Si interface, this compressive stress is consistent with an increased volume of the Ti cell.

\section{$\underline{\text { G1 grains }}$}

In the case of (101) oriented grains, the sample compliance tensor has to be adapted to account for the angle $\left(\alpha \approx 61^{\circ}\right)$ between the film normal and the hexagonal c-axis. The transformed sample tensor was thus obtained by applying the rotation matrix relating crystal to sample axis following Eq. 11. This altered the relationships between tensor elements because the (101) planes are not elastically isotropic and additional in-plane shear components appear in the elastic compliance tensor. The resulting compliance matrix is given in Table 1b. However, as no $\phi$ dependence was detected in our strain data, it is likely that an averaging effect coming from the fiber texture results in a pseudo-isotropic deformation of these grains. 
This effect called orthotropic symmetry is usually observed in fiber textured materials with no in-plane specific orientation. According to this assumption, a $\phi$ averaging calculation of the $\mathrm{G} 1 \mathrm{~S}_{\mathrm{ijk}}$ tensor was made, followed by $\phi$ integration $(0 \leq \phi \leq 2 \pi)$ of each tensor component. This operation restored the hexagonal-type symmetry rules in the tensor, as shown in Table 1c. Once the new pseudo-hexagonal values were obtained, it was then possible to resume the data processing from Eqs. 15 and 16, assuming

$\frac{\mathrm{c}^{\prime} 0}{\mathrm{a}^{\prime} 0}=\frac{\mathrm{c}}{\mathrm{a}}=1.622$ (see Table 3 ). The stress values obtained in the as-deposited and annealed samples was $270 \mathrm{MPa}$ and $+880( \pm 250) \mathrm{MPa}$ respectively.

The opposite change from G1 to G2 grains is quite surprising. This is probably related to the G1 volume fraction: G1 grains are scattered in the G2 matrix and probably limit the use of a continuous and planar thin film model. This limitation probably appears in the scattering of G1 data (see linear variation in Fig. 2c). Another possibility to account for the opposite change is a slight difference in the Si content between both types of grains.

\section{3-d Analysis of stress-free lattice parameters}

An analysis of the alloyed stress-free parameters was made by considering local environments and interatomic distances in a series of Ti silicide compounds and then, by using simple Vegard's law to obtain the $\mathrm{Si}$ content in Ti grains.

\section{a) Silicide interatomic distance analysis}

To evaluate the variation of interatomic distances as a function of Si content, a detailed investigation of the Si local environment was carried out in the whole silicide family, from $\mathrm{Ti}_{5} \mathrm{Si}_{3}, \mathrm{TiSi}, \mathrm{C} 49$ and C54 $\mathrm{TiSi}_{2}$. Results are reported in Table $2^{2,}{ }^{15-20}$. As no accurate $\mathrm{Ti}_{5} \mathrm{Si}_{4}$ crystal data were available, this composition was not included in our data series.

The composition of the nearest environment of a Si atom changes naturally with Si content. For Tirich compositions $\left(\mathrm{Ti}_{5} \mathrm{Si}_{3}\right)$, this environment is only made of Ti atoms. Moreover it is possible to see a modified octahedral geometry if the two more distant $\mathrm{Ti}$ atoms $(\mathrm{Ti}-\mathrm{Si}=0.28 \mathrm{~nm}$ ) are not taken into account: $4 \mathrm{Ti}$ atoms at a $0.2632 \mathrm{~nm}$ distance, $2 \mathrm{Ti}$ atoms at $0.2572 \mathrm{~nm}$ (instead of one in a real octahedral geometry) and an additional one at $0.2679 \mathrm{~nm}$. For higher Si content, the octahedral type local environment is progressively modified.

The evolution of the mean interatomic distances is displayed in Fig. 3 where $\left\langle\mathrm{d}_{\mathrm{Ti}-\mathrm{Si}}\right\rangle$ refers to averaged Ti-Si interatomic distances for the nearest Si neighbours and $<\mathrm{d}>$ to the average of $\mathrm{Ti}-\mathrm{Si}+\mathrm{Si}-\mathrm{Si}$ distances. The threshold distance used to select $\mathrm{Si}-\mathrm{Si}$ nearest neighbours was $0.300 \mathrm{~nm}$. In all cases, the next nearest neighbours are further than $0.32 \mathrm{~nm}$ ( $\mathrm{Si}-\mathrm{Si}$ bonding) and $0.42 \mathrm{~nm}(\mathrm{Si}-\mathrm{Ti})$. It appears that the average Ti-Si distance is comparable in all the silicides (between 0.2635 and $0.2673 \mathrm{~nm}$ ). 
From this analysis, a Si insertion in $\alpha$-Ti is more likely to occur on the large octahedral sites. This location is also very likely because the local environment of the first formed Ti-rich silicide closely resembles the six nearest neighbour environment of the octahedron.

\section{b) Si content in Ti grains}

By assuming Si insertion on a regular octahedral site where the center to apex distance is $0.266 \mathrm{~nm}$ (i.e. the mean $\mathrm{Si}-\mathrm{Ti}$ distance estimated from the silicide series), the c/a ratio can be expected to vary from $\mathrm{c} / \mathrm{a}=1.585$, observed in the as-deposited sample, to values closer to the ideal close compact ratio : 1.633. Results of lattice parameter refinements from the raw d-spacing data are given in Table 3 . They indicate that annealing does not distort the hexagonal crystal system but does have a dramatic effect on the c/a ratio ( $a$ and c parameters including mechanical and alloying effects). The ratio changes from 1.585 for the asdeposited sample to 1.622-1.604 for the annealed samples. These results seem to support the $\mathrm{Si}$ insertion hypothesis.

As mentioned in Section 2, to estimate the Si content in Ti grains, we suppose now that the ideal c/a axis ratio (1.633) is retained. The stress-free lattice parameters $a_{0}^{\prime}$ and $c_{0}^{\prime}$ associated with partially occupied octahedral sites can thus be obtained from the stress-free lattice spacings $\left(\mathrm{d}^{\prime}{ }_{0}\right)_{\mathrm{hkl}}($ Table 3$)$.

Assuming a hypothetical octahedral site fully occupied with Si where the Si-Ti distances are all equal to the mean $\mathrm{Si}-\mathrm{Ti}$ distance detected in the silicide compound series, the $\mathrm{Si}$ concentration in the alloyed Ti is calculated according to a simple Vegard's law

$$
\mathrm{xSi}_{\mathrm{i}}=\frac{\mathrm{V}_{0}^{\prime}-\mathrm{V}_{0}}{\mathrm{~V}_{\mathrm{hc}}-\mathrm{V}_{0}}
$$

where $\mathrm{x}_{\mathrm{Si}}$ is the $\mathrm{Si}$ occupation rate of the Ti octahedral sites $(\%), \mathrm{V}_{0}$ the unit-cell volume of the asdeposited $\mathrm{Ti}, \mathrm{V}_{0}^{\prime}$ the unit-cell volume of the alloyed $\mathrm{Ti}$ and $\mathrm{V}_{\mathrm{hc}}$ the unit-cell volume of the hexagonal close compact $\mathrm{Ti}$. $\mathrm{V}_{\mathrm{hc}}$ was obtained from the mean $\mathrm{Si}$-Ti distance in a perfect octahedron: $\mathrm{V}_{\mathrm{hc}}=\mathrm{a}_{\mathrm{hc}}^{2} \mathrm{c}_{\mathrm{hc}} \frac{\sqrt{3}}{2}$, with $\mathrm{a}_{\mathrm{hc}}=<\mathrm{d}_{\mathrm{Si}}-\mathrm{Ti}>\frac{2}{\sqrt{2}}=0.376 \mathrm{~nm}$ and $\frac{\mathrm{c} \mathrm{hc}}{\mathrm{ahc}}=1.633$. The calculations yield 4.9 $( \pm 0.5)$ and $4.3( \pm 0.5)$ atomic $\% \mathrm{Si}$ in the $\mathrm{G} 2$ and $\mathrm{G} 1$ grains, respectively. If the octahedral sites were all occupied, the composition would be $\mathrm{Ti}_{2} \mathrm{Si}$. The site occupation observed here gives a composition close to $\mathrm{Ti}_{2} \mathrm{Si}_{0.045}$. This 4.5 at\% Si content is significantly higher than the solubility limit of $\mathrm{Si}$ in bulk crystallized $\mathrm{Ti}(\approx 1.0 \%)$ but close to values obtained from amorphous or finely divided $\mathrm{Ti}^{21}$. The film microstructure observed in our annealed films is similar to the latter situation.

Although no significant difference in the Si content clearly appears in our stress-free lattice parameter analysis, small differences could support the opposite stress behaviour discussed in Section 3c.

Finally, by analyzing the stress developed in the very first stages of diffusion, it was possible to show that diffusion is favoured at low temperature by a compressive in-plane stress possibly resulting 
from the filling of grain boundaries by Si. Then, once intra-grain diffusion occurs, stress considerably relaxes, and the major component in the lattice parameter increase observed using XRD comes from $\mathrm{Si}$ alloying of Ti grains. Further investigation of Si diffusion will be made by performing in-situ Spectroscopic Photo-Emission and Low Energy Electron Microscopy (SPELEEM) experiments.

\section{Conclusion}

The first stages of silicidation in Ti/Si thin films were studied by X-ray diffraction from fiber textured films where two major grain families are present : 001 (amounting to $90 \%$ of the volume) and 101 (about $10 \%$ ). In a temperature range lower than that needed for the formation of crystallized silicide, X-ray diffraction experiments provide clues for Si diffusion starting from $360^{\circ} \mathrm{C}$. First, it proceeds by Ti grain-boundary diffusion which develops a very compressive stress on the Ti grains. At higher temperatures, intra-grain diffusion is detected from the observed broadening of the diffraction profiles. An ex-situ stress/strain analysis of as-deposited and annealed Ti/Si films indicates $\mathrm{G} 2$ grains must be under a compressive stress at annealing temperatures close to $478^{\circ} \mathrm{C}: \sigma_{\text {as-dep }}=+270 \mathrm{MPa}, \sigma_{\text {ann }}=-155( \pm 50) \mathrm{MPa}$. Even though the G1 grains are scattered in the G2 matrix, which probably limits the use of a continuous and planar thin film model, the G1 grain behaviour has been determined. It is opposite to G2: $\sigma_{\text {as-dep }}=-270$ $\mathrm{MPa}, \sigma_{\mathrm{ann}}=+880( \pm 250) \mathrm{MPa}$. An analysis of the Si local environment and interatomic distances in the Ti silicide family from $\mathrm{Ti}_{5} \mathrm{Si}_{3}$ to $\mathrm{TiSi}_{2}$ combined with the stress analysis, shows that the stress-free lattice parameters of annealed Ti films are higher than the bulk parameters; the calculation of Si concentration in the alloyed Ti according to Vegard's law indicates that nearly 4.5 at.\% Si is present in the Ti grains. 


\section{References}

F.M. d'Heurle, O. Thomas, Defect and Diffusion Forum 129-130, 137 (1996) .

2 B. Chenevier, O. Chaix-Pluchery, I. Matko, F. La Via, J. P. Sénateur and R. Madar, Appl. Phys. Lett. 79, 2184 (2001) .

3 I. Matko, B. Chenevier, O. Chaix-Pluchery, R. Madar, F. La Via, Thin Solid Films 408, 123 (2002).

4 B. Chenevier, O. Chaix-Pluchery, I. Matko, R. Madar, F. La Via, Microelectronic Engineering, 64, 181 (2002) .

5 E. R. Weber, Mater. Res. Soc. Symp. Proc. 36, 3 (1985).

G.W. Rubloff, R.M. Tromp, E.J. van Loenen, Appl. Phys. Lett. 48, 1600 (1986).

K. Holloway, R. Sinclair,-, J. Appl. Phys. 61, 1359 (1987) .

I.C. Noyan, J.B. Cohen, Residual stress : measurement by diffraction and interpretation (Springer-Verlag, New-York, 1987) p146.

$9 \quad$ B.M. Clemens, J.A. Blain, MRS Bulletin 17, 46 (1992).

10 J.F. Nye, Physical Properties of crystals (Clarendon Press; Oxford University Press, 1985).

11 S. Labat, P. Gergaud, O. Thomas, B. Gilles, A. Marty, J. Appl. Phys. 87, 1172 (2000).

12 W. Lur, L.J. Chen, Appl. Phys. Lett. 54, 1217 (1989).

13 J.B. Lai, L.J. Chen, J. Appl. Phys. 89, 6110 (2001).

H. Tanaka, T.J. Konno, R. Sinclair, N. Hirashita, J. Appl. Phys. 78, 4982 (1995).

15 Standard JCPDS diffraction pattern 44-1294 (hexagonal Ti), JCPDS-International Center for Diffraction Data, PDF-2 Data-base, 12 Campus Boulevard, Newton Square, PA 19073-3273.

16 Standard JCPDS diffraction pattern 78-1429 (hexagonal $\mathrm{Ti}_{5} \mathrm{Si}_{3}$ ).

17 T. Kajitani, T. Kawase, K. Yamada and M. Hirabayashi, Trans. Jpn. Inst. Met. 27, 639 (1986).

18 Standard JCPDS diffraction pattern 17-0424 (orthorhombic TiSi).

19 W. B. Pearson, a Handbook of Lattice Spacings and Structures of Metals and Alloys, (Pergamon, New-York, 1967) Vol. 2.

20 L.F. Mattheiss, J.C. Hensel, Phys. Rev. B 39, 7754 (1989).

21 R. Madar (private communication). 


\section{Figure captions}

\section{Figure 1 :}

Expansion of the Ti lattice in Ti/Si thin films on annealing. Evolution of d-spacings (a) and FWHM values (b) for both 002 (opened symbols) and 101 (full symbols) Ti diffraction lines. Four temperature domains refer to conventional thermal expansion (I), Si diffusion in Ti grain boundaries (II), Si diffusion in Ti grains (III) and formation of the first crystallized silicides, $\mathrm{Ti}_{5} \mathrm{Si}_{3}$ and then $\mathrm{C} 49 \mathrm{TiSi}_{2}$ at $540^{\circ} \mathrm{C}$ (IV). Error bars are important in domains III-IV because the Ti line intensities are very small.

\section{Figure 2 :}

Strain variation $\left(\varepsilon=\left(d-d_{0}\right) / d_{0}\right)$ as a function of $\sin ^{2} \psi$ for as-deposited Ti films (a), as well as for Ti films annealed at $478^{\circ} \mathrm{C}$ : (b) (001) oriented Ti grains (G2), $\sin ^{2} \psi_{0}=0.42, \varepsilon_{0}=0.0197$ and (c) (101) oriented Ti grains (G1), $\sin ^{2} \psi_{0}=0.49, \varepsilon_{0}=0.0171$. In (b) and (c), opened symbols refer to strains obtained from raw d-spacing data, full symbols to strains corrected from the alloying effect contribution.

\section{Figure 3 :}

Averaged interatomic distance values between nearest neighbours in the Ti silicide family. $<\mathrm{d}_{\mathrm{Ti}-\mathrm{Si}}>$ refers to $\mathrm{Ti}-\mathrm{Si}$ and $<\mathrm{d}>$ to the average of $\mathrm{Ti}-\mathrm{Si}+\mathrm{Si}-\mathrm{Si}$. $\mathrm{n}$ is the number of the nearest neighbours to a Ti. In $\mathrm{Ti}_{5} \mathrm{Si}_{3}$ and $\mathrm{C} 49 \mathrm{TiSi}_{2}$, there are two distinct $\mathrm{Ti}$ and $\mathrm{Si}$ sites, respectively; $\mathrm{n}$ gives the number of the nearest neighbours related to each site ( $4+5$ and $4+6$, respectively). 


\section{Table 1}

Compliance matrices relative to $\mathrm{G} 2 \mathrm{~S}_{\mathrm{ijk}}$ tensor (a), G1 $\mathrm{S}_{\mathrm{ijk}}$ tensor (b) and G1 $\mathrm{S}_{\mathrm{ijkl}}$ tensor after $\phi$ averaging and integration $(0 \leq \phi \leq 2 \pi)$ calculation of all the tensor components (c).

(a)

$$
\left(\begin{array}{cccccc}
0.97 & -0.47 & -0.18 & 0 & 0 & 0 \\
-0.47 & 0.97 & -0.18 & 0 & 0 & 0 \\
-0.18 & -0.18 & 0.69 & 0 & 0 & 0 \\
0 & 0 & 0 & 0.5375 & 0 & 0 \\
0 & 0 & 0 & 0 & 0.5375 & 0 \\
0 & 0 & 0 & 0 & 0 & 0.72
\end{array}\right) \times 10^{-11} \mathrm{~Pa}^{-1}
$$

(b)

$\left(\begin{array}{cccccc}0.97 & -0.2468 & -0.4033 & -0.1221 & 0 & 0 \\ -0.2468 & 0.7776 & -0.2031 & 0.0737 & 0 & 0 \\ -0.4033 & -0.2031 & 0.9287 & 0.0442 & 0 & 0 \\ -0.1221 & 0.0737 & 0.0442 & 0.5145 & 0 & 0 \\ 0 & 0 & 0 & 0 & 0.6780 & 0.0768 \\ 0 & 0 & 0 & 0 & 0.0768 & 0.5795\end{array}\right) \times 10^{-11} \mathrm{~Pa}^{-1}$

(c)

$$
\left(\begin{array}{cccccc}
0.6661 & -0.0391 & -0.3032 & 0 & 0 & 0 \\
-0.0391 & 0.6661 & -0.3032 & 0 & 0 & 0 \\
-0.3032 & -0.3032 & 0.9287 & 0 & 0 & 0 \\
0 & 0 & 0 & 0.5962 & 0 & 0 \\
0 & 0 & 0 & 0 & 0.5962 & 0 \\
0 & 0 & 0 & 0 & 0 & 0.4975
\end{array}\right) \times 10^{-11} \mathrm{~Pa}^{-1}
$$


Table 2

Crystallographic data in Ti and Ti silicide family.

\begin{tabular}{|c|c|c|c|c|c|}
\hline & Bulk Ti & $\mathbf{T} \mathbf{i}_{5} \mathbf{S} \mathbf{i}_{3}$ & TiSi & $\mathrm{TiSi}_{2} \mathrm{C} 49$ & $\mathrm{TiSi}_{2} \mathbf{C 5 4}$ \\
\hline Space group & $\begin{array}{l}\mathrm{P}_{3} / \mathrm{mmc} \\
\text { (hexagonal) }\end{array}$ & $\begin{array}{c}\mathrm{P}_{3} / \mathrm{mcm} \\
\text { (hexagonal) }\end{array}$ & $\begin{array}{l}\text { Pnma } \\
\text { (orthorhombic) }\end{array}$ & $\begin{array}{l}\mathrm{Cmcm} \\
\text { (orthorhombic) }\end{array}$ & $\begin{array}{c}\text { Fddd } \\
\text { (orthorhombic) }\end{array}$ \\
\hline 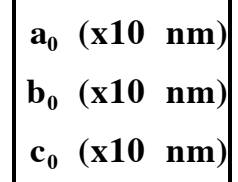 & 4.6826 & 5.1508 & $\begin{array}{l}6.544 \\
3.638 \\
4.997\end{array}$ & $\begin{array}{c}3.557 \\
13.776 \\
3.518\end{array}$ & $\begin{array}{l}8.244 \\
4.793 \\
8.520\end{array}$ \\
\hline References & 15 & 16,17 & 18 & 2 & 2 \\
\hline $\begin{array}{c}\text { Atomic } \\
\text { positions }\end{array}$ & Ti $2 \mathrm{c}: 1 / 3,2 / 3,1 / 4$ & $\begin{array}{l}\text { Ti1 4c: } 0.179,1 / 4,0.127 \\
\text { Ti2 6g: } 0.2473,0,1 / 4 \\
\text { Si 6g: } 0.6063,0,1 / 4\end{array}$ & $\begin{array}{l}\text { Ti 4c: } 0.1796,1 / 4,0.127 \\
\text { Si 4c: } 0.030,1 / 4,0.620\end{array}$ & $\begin{array}{l}\text { Ti 4c: } 0,0.1022,1 / 4 \\
\text { Si1 4c: } 0,0.7522,1 / 4 \\
\text { Si2 4c: } 0,0.4466,1 / 4\end{array}$ & $\begin{array}{l}\text { Ti 8a: } 0,0,0 \\
\text { Si 16e: } 0.3365,0,0\end{array}$ \\
\hline References & 19 & 19 & 19 & 20 & 19 \\
\hline $\begin{array}{c}\text { Interatomic } \\
\text { distances } \\
\left(\begin{array}{ll}\mathbf{x} 10 & \mathbf{n m})\end{array}\right.\end{array}$ & $\begin{array}{rr}\text { Ti-Ti: } 2.9505 \quad \mathrm{x} 6 \\
2.8939 \times 6 \\
\\
<\mathbf{d}_{\text {Ti-Ti }}>2.9222 \times 12\end{array}$ & $\begin{array}{rl}\text { Ti1-Ti2: } 2.5754 & \text { x2 } \\
\text { Ti2-Ti2: } 3.1682 & \text { x4 } \\
3.1958 & \text { x2 } \\
\text { Ti1-Ti2: } 3.1388 & \text { x6 } \\
<\mathbf{d}_{\text {Ti-Ti }}>3.0748 & \text { x14 } \\
\text { Si-Ti1: } 2.6318 & \text { x4 } \\
<\mathbf{d}_{1}>2.6318 & \mathrm{x} 4 \\
\text { Si-Ti2: } 2.7975 & \mathrm{x} 2 \\
2.5716 & \mathrm{x} 2 \\
2.6785 & \mathrm{x} 1 \\
<\mathbf{d}_{2}>2.6833 & \mathrm{x} 5 \\
<\mathbf{d}_{\text {Si-Ti }}>2.6604 & \mathrm{x} 9 \\
\text { Si-Si: } \quad(3.0247) & \\
& \\
& \\
<\mathbf{d}>2.6604 & \mathrm{x} 9\end{array}$ & $\begin{array}{rr}\text { Ti-Ti: } 3.4953 & \mathrm{x} 2 \\
3.2272 & \mathrm{x} 2 \\
3.2262 & \mathrm{x} 2 \\
& \\
& \\
<\mathbf{d}_{\text {Ti-Ti }}>3.3162 & \mathrm{x} 6 \\
\text { Si-Ti: } 2.6034 & \mathrm{x} 2 \\
2.6337 & \mathrm{x} 2 \\
2.6495 & \mathrm{x} 1 \\
2.6076 & \mathrm{x} 1 \\
2.7146 & \mathrm{x} 1 \\
& \\
& \\
<\mathbf{d}_{\text {Si-Ti }}>2.6351 & \mathrm{x} 7 \\
\text { Si-Si: } 2.2139 & \mathrm{x} 2 \\
& \\
& \\
<\mathbf{d}>2.5415 & \mathrm{x} 9\end{array}$ & 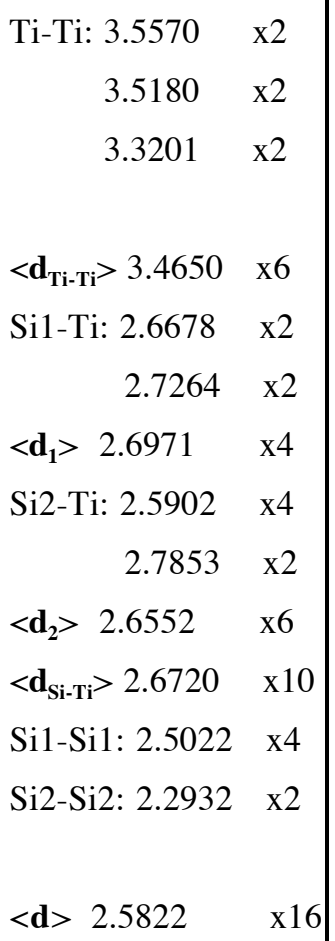 & 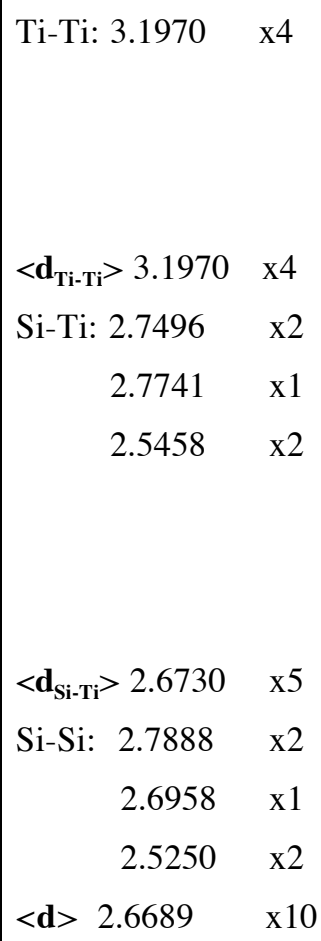 \\
\hline
\end{tabular}




\section{$\underline{\text { Table } 3}$}

Lattice parameters values of bulk $\mathrm{Ti}$, as-deposited $\mathrm{Ti}\left(\mathrm{a}_{0}, \mathrm{c}_{0}\right)$ and $\mathrm{Ti}$ annealed at $478^{\circ} \mathrm{C}(\mathrm{a}, \mathrm{c})$; stress-free lattice parameters values of annealed $\mathrm{Ti}\left(\mathrm{a}_{0}^{\prime}, \mathrm{c}_{0}^{\prime}\right)$; Si content in Ti grains $\left(\mathrm{x}_{\mathrm{Si}}\right) .10$ and 9 reflections were respectively measured for (101) (G1) and (001) oriented grains (G2). a,c and Si content uncertainties are given in parenthesis.

\begin{tabular}{|c|c|c|c|c|c|}
\hline & \multirow[t]{2}{*}{ bulk Ti } & \multicolumn{2}{|c|}{ as-deposited $\mathbf{T i}$} & \multicolumn{2}{|c|}{ Ti annealed at $\mathrm{T}=478^{\circ} \mathrm{C}$} \\
\hline & & G1 & G2 & G1 & G2 \\
\hline $\begin{array}{c}\mathbf{a} \\
(\mathrm{x} 10 \mathrm{~nm})\end{array}$ & 2.9505 (1) & $2.9544(7)$ & $2.950(3)$ & $2.972(6)$ & $2.992(2)$ \\
\hline $\begin{array}{c}\mathbf{c} \\
(\mathrm{x} 10 \mathrm{~nm})\end{array}$ & $4.6826(3)$ & $4.679(2)$ & $4.679(1)$ & $4.82(2)$ & $4.798(3)$ \\
\hline $\mathbf{c} / \mathbf{a}$ & 1.587 & 1.584 & 1.586 & 1.622 & 1.604 \\
\hline $\begin{array}{c}\mathbf{a}_{\mathbf{0}}^{\prime} \\
(\mathrm{x} 10 \mathrm{~nm})\end{array}$ & & - & - & $2.978(4)$ & 2.9949 (1) \\
\hline $\begin{array}{c}\mathbf{c}_{\mathbf{0}}^{\prime} \\
(\mathrm{x} 10 \mathrm{~nm})\end{array}$ & & - & - & $4.828(12)$ & $4.7921(1)$ \\
\hline $\begin{array}{c}\text { Si content } \\
\text { (at. \%) }\end{array}$ & & & & $4.3(5)$ & $4.9(5)$ \\
\hline
\end{tabular}



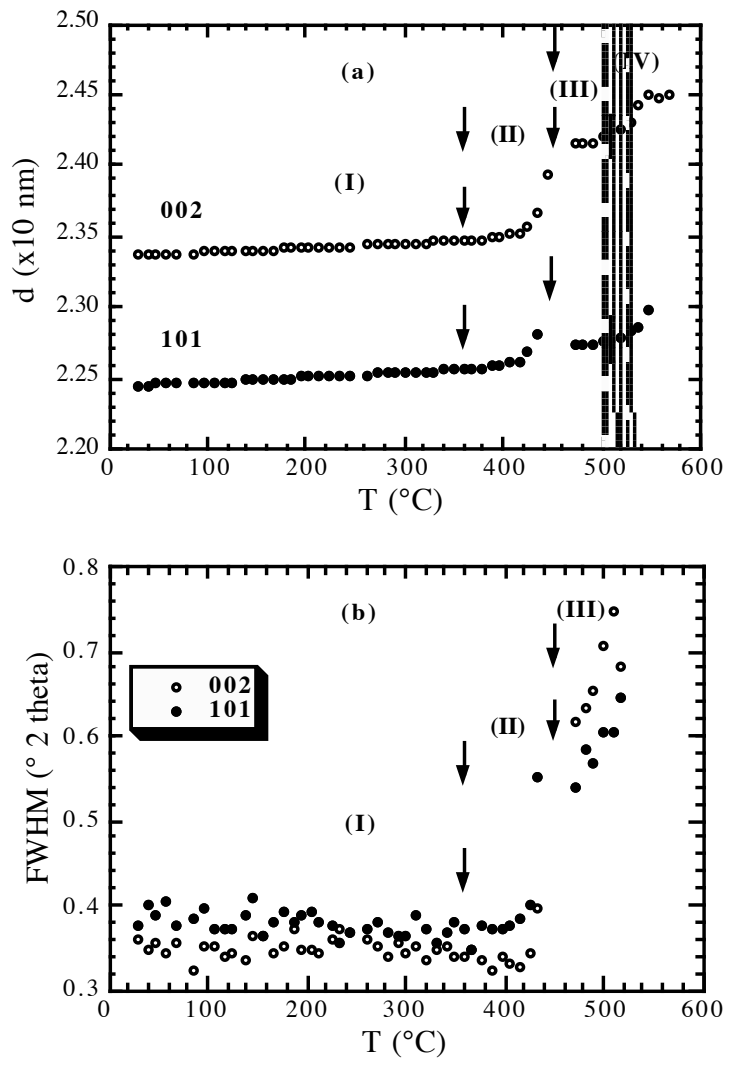

Fig. 1 

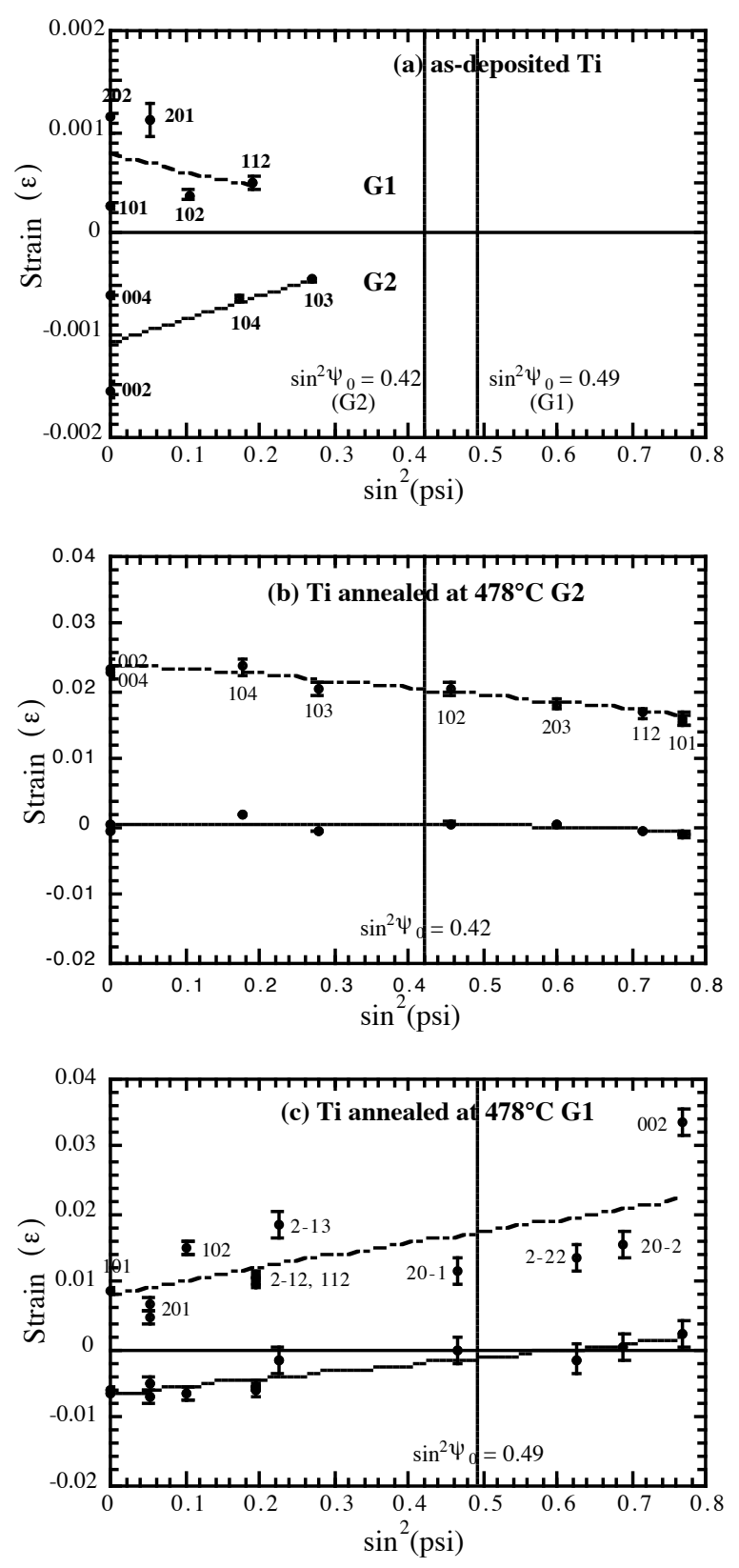

Fig.2 


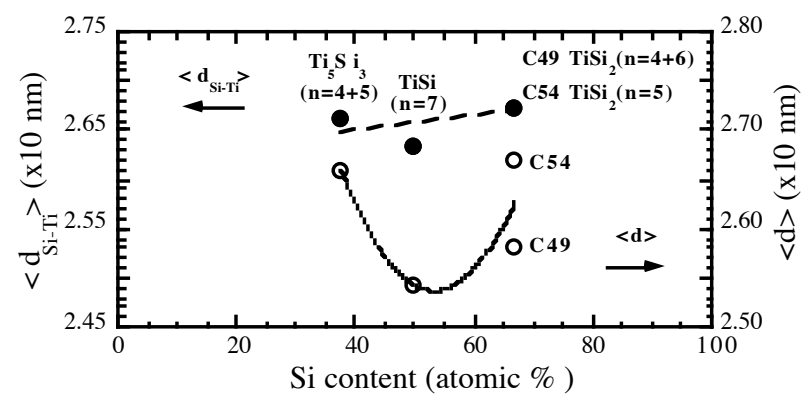

Fig. 3 